\title{
A biblioteca pública e seu projeto político: entre a conformação e o pensamento
}

\begin{abstract}
Fabíola Farias
\end{abstract}
\begin{abstract}
Graduada em Letras com mestrado em Ciência da Informação. Doutoranda em Ciência da Informação pela Escola de Ciência da Informação - ECI/UFMG.
\end{abstract}

http://dx.doi.org/10.1590/1981-5344/2292

Este ensaio discute a função da biblioteca pública, tendo como eixo as crenças que sustentam suas proposições e serviços. Entre o prioritário atendimento a demandas da comunidade e oferta de serviços tradicionais e a proposição de um projeto que tenha no horizonte a educação intelectual da população por meio da letra, a biblioteca pública busca seu lugar entre a conformação e o pensamento. Uma ou outra concepção norteará toda a ação bibliotecária, desde a seleção do acervo bibliográfico às atividades a serem desenvolvidas.

Palavras-chave: Bibliotecas públicas. Leitura. Políticas públicas. Educação intelectual.

\section{Public library and its political project: between conformation and thought.}

This essay discusses the role of the public library, having as the axis the beliefs that support their propositions and services. Among the priority care of community'sdemands, the offering of traditional services and the proposition of a project that aims the intellectual education of the population through the letter, the public library seeks its place among the conformation and thought. One of the conceptualdesign will guide all librarianaction, from the selection of a bibliographic collection to activities to be developed.

Keywords: Public library. Reading. Public policy. Intellectual education. 
As palavras sonho [somnium] e símbolo [súmbolon], por exemplo, foram as primeiras a desaparecer (não ouso reproduzir o som do veneno que as eliminou.

(Marcílio França Castro) ${ }^{1}$

A biblioteca pública representa, para a maioria da população brasileira e no âmbito das políticas públicas para a democratização do acesso à leitura no país, a maior possibilidade de educação permanente por meio do conhecimento registrado pela letra. Junto às bibliotecas comunitárias, que são iniciativas implantadas, geridas e mantidas pela sociedade civil, as bibliotecas públicas são a garantia de acesso a livros e outros materiais de leitura, em suportes físicos e eletrônicos, para crianças e jovens em idade escolar, mas também para adultos que nunca fizeram ou já não fazem mais parte do sistema de educação formal. Num país como o Brasil, onde o poder aquisitivo médio da população não permite que livros façam parte da cesta básica da grande maioria das famílias, as bibliotecas públicas e também as comunitárias, representam, em resumo, a possibilidade de leitura antes, durante e depois da escola.

Historicamente, a compreensão do que seja e de para que serve a biblioteca pública vem sendo constantemente modificada, de acordo com o contexto socioeconômico mundial: desde um lugar para a instrução das pessoas para o mundo industrializado e para os novos mercados de trabalho, até a proposição de um espaço para a educação permanente da população, passando por tentativas de manutenção da ordem pública pela leitura e atividades de entretenimento, pela preocupação com a preservação e difusão do conhecimento e várias nuances e ramificações destas abordagens mais amplas, como relata Suzana Mueller (1984).

O primeiro e mais importante passo para a discussão da biblioteca pública, dos seus desafios e obstáculos é compreender do que falamos quando falamos de biblioteca pública, para evitar o discurso esvaziado e a sedução do pensamento reificado, que geram e sustentam proposições, projetos e ações inconsistentes.

Para Theodor Adorno, mais que o conhecimento específico da disciplina ou do objeto de trabalho em questão, é na reflexão sobre ela mesma, sua razão de ser, que se instala a resistência contra a aceitação de uma consciência reificada, que, sem nem mesmo perceber que o faz, admite a vida e as coisas como alguém um dia disse que elas são ou deveriam ser. As considerações que tece acerca dos futuros professores de filosofia, objeto do seu estudo em dado momento, também se aplicam aos professores, bibliotecários, pesquisadores e demais profissionais que lidam com a formação de leitores:

que os futuros professores tenham uma luz quanto ao que eles próprios fazem, em vez de se manterem desprovidos de conceitos em relação à sua atividade. (...) A auto-reflexão e o esforço crítico são dotados por isso de uma possibilidade real, a qual seria precisamente o contrário daquela dedicação férrea pela qual a

\footnotetext{
${ }^{1}$ A casa dos outros. Rio de Janeiro: 7 Letras, 2009.
} 
maioria se decidiu. Esta contraria a formação cultural e a filosofia, na medida em que de antemão é definida pela apropriação de algo previamente existente e válido, em que faltam o sujeito, formando ele próprio, seu juízo, sua experiência, o substrato da liberdade. (ADORNO, 1995, p. 69)

Na tentativa de expor didaticamente nossos argumentos, trabalharemos aqui com duas ideias de biblioteca pública radicalmente antagônicas, embora nem sempre o antagonismo e o conflito entre os dois modelos sejam perceptíveis tão facilmente para aqueles menos experientes e atentos. Para isso, lançaremos mão de duas narrativas literárias.

T. J. Clark, historiador da arte e professor na Universidade da Califórnia, ao discutir a pertinência e os rumos da esquerda no mundo contemporâneo, destaca o marxismo como forma privilegiada de compreensão da sociedade burguesa e afirma que, ainda assim, a literatura o extrapola:

Em suas melhores formulações (no próprio Marx, no Lukács dos anos 1920, em Gramsci, em Benjamin, em Attila József, no Sartre de "La Conscience de classe chez Flaubert"), o marxismo foi mais fundo na textura das crenças e práticas burguesas do que qualquer outra forma de representação descritiva, com exceção do romance." (CLARK, 2013, p. 39)

Roland Barthes, em sua aula inaugural no Collège de France, em 1977, também conferia à literatura essa mesma potência de dizer o mundo: "[...] a literatura, quaisquer que sejam as escolas em nome das quais ela se declara, é absolutamente, categoricamente realista: ela é realidade, isto é, o próprio fulgor do real" (BARTHES, [19--], p. 18).

Dessa maneira, mesmo não sendo ciência, é a literatura, a fabulação, que provocará a discussão proposta para este artigo. A partir de duas narrativas, problematizaremos projetos distintos de bibliotecas públicas e de que maneira, apoiados em quais crenças, a ação bibliotecária se realiza.

A primeira narrativa pertence à mitologia grega e mostra Teseu na busca pelo pai. Num de seus desafios, o herói enfrenta o sanguinário Polipêmon, apelidado de Procrusto, isto é, "aquele que estica":

O criminoso assassino usava de uma 'técnica' singular com suas vítimas: deitava-as em um dos dois leitos de ferro que possuía, cortando os pés dos que ultrapassavam a cama pequena ou distendia violentamente as pernas dos que não preenchiam o comprimento do leito maior. (BRANDÃO, 2000, p. 156) 
Ao agir dessa maneira, Procrusto deixava suas vítimas com um tamanho padrão, definido previamente pelo comprimento de suas camas de ferro, instrumentos de sua crueldade. Procrusto representa uma tentativa de conformação, na medida em que todas as suas vítimas são marcadas, esticadas umas e amputadas outras, com o mesmo tamanho, com o mesmo jeito e igualmente mutiladas. O monstro foi vencido por Teseu, mas seu espírito nunca abandonou os homens, especialmente nos tempos que correm.

O conto Um general na biblioteca, do escritor italiano Ítalo Calvino, é a segunda narrativa que conduzirá a discussão aqui proposta. Diante da desconfiança de que os livros poderiam conter opiniões contrárias ao prestígio militar, a biblioteca da cidade é fechada pelo Estado-maior da Panduria para que os soldados, comandados pelo general Fedina, possam investigar o que pode ou não ser lido pelos habitantes. Porém, à medida que lêem os livros, ajudados por Crispino, o velho bibliotecário, o único que tinha sido autorizado a permanecer na biblioteca com os soldados, mais que o que procuram - as opiniões contrárias ao prestígio militar -, eles começam a encontrar e descobrir o que até então nunca haviam buscado. Dessa maneira, eram cada vez mais escassos os boletins que os soldados apresentavam aos seus superiores, o que deixou alarmado o comando supremo, que ordenou que a investigação deveria ser concluída o quanto antes, com a apresentação de um exaustivo relatório.

A ordem chegou à biblioteca quando o espírito de Fedina e de seus homens se debatia entre sentimentos opostos: por um lado, estavam descobrindo a todo instante novas curiosidades a serem satisfeitas, estavam tomando gosto por aquelas leituras e aqueles estudos como nunca antes teriam imaginado; por outro, não viam a hora de voltar para junto das pessoas, de retomar contato com a vida, que agora thes parecia muito mais complexa, quase renovada aos olhos deles; e, além disso, a aproximação do dia em que deveriam deixar a biblioteca enchia-os de apreensão, pois teriam de prestar contas de sua missão, e, com todas as idéias que andavam brotando em suas cabeças, não sabiam mais como sair dessa enrascada. (CALVINO, 2001, p. 78)

Assim, as leituras e a biblioteca, mesmo interditada, suscitaram nos soldados, especialmente no general Fedina, a curiosidade e o desejo de conhecer mais, para além do que procuravam e até mesmo em conflito com isso. E, para eles, ali já não bastava saber, era necessário voltar para junto das pessoas para viver e falar dessa vida tão complexa. É importante destacar, ainda, a presença do bibliotecário Crispino no conto, com sua atuação inteligente e habilidosa no cumprimento de sua missão. À medida que os soldados se perdiam entre montanhas de livros, com ideias distintas e contraditórias entre si, o velho Crispino estimulava a desorientação aparente, apresentando e falando de outros livros e autores com pensamentos ainda mais divergentes. Mas o que fazia o bibliotecário 
era oferecer caminhos para o desvendamento de um mundo que é, de fato, desorganizado, conflituoso, convidando cada um de seus soldadosleitores a questionar o que parecia tão natural e harmônico e a pensar livremente sobre ele, com todas as suas contradições.

O senhor Crispino, silencioso dentro de suas pantufas, quase invisível dentro de seu jaleco cinza, sempre intervinha na hora certa, com um livro que a seu ver continha detalhes interessantes sobre o tema em questão, e cujo efeito era sempre de pôr à prova as convicções do general Fedina. (CALVINO, 2001, p. 77)

Procrusto e Crispino. O primeiro, organizando tudo sistemática e cruelmente, com método e sem concessões; todos do mesmo tamanho, com o mesmo formato, de acordo com um modelo previamente estabelecido. O segundo, na contramão, desorganizando o mundo, as ideias, as certezas, expondo conflitos para quem veio justamente em busca de uma história única. Procrusto atende ao desejo de muitos: governantes autoritários que reduzem a democracia às eleições, à forma de acesso ao poder, e se sentem incomodados e enraivecidos com as tentativas de participação popular na condução das políticas públicas; professores inseguros (con)formados para instruir, não para educar, que pedem silêncio e ordem todo o tempo, que não suportam extrapolar o plano de aula ou mais perguntas no lugar das respostas oferecidas nas últimas páginas dos livros didáticos, devotados ao sistema produtivo, que transforma o conhecimento em competências; bibliotecários seduzidos pela ordem de letras e números, pelos softwares de organização de acervos e arquivos, pela suspensão ou multa em função de devoluções atrasadas, mais dedicados aos livros que aos leitores. Já Crispino incomoda a maioria, pois habilmente expõe a desordem do mundo, os conflitos humanos, a história escrita por muitos e diversos e guardada pela letra; reconhece as contradições da vida e se atreve a buscá-las cada vez mais.

As bibliotecas, não somente as públicas, têm como característica comum a guarda, a organização e a disponibilização do conhecimento registrado pela letra. Assim, dito de maneira bastante resumida, elas oferecem às pessoas a história, a literatura, a filosofia, a matemática, a física, o esoterismo, a religião, enfim, todas as formas de narrativa e de pensamento que em algum lugar e no tempo passado foram registradas por alguém pela escrita. O acesso autônomo a esse conhecimento guardado pela letra é restrito a quem sabe ler. As pessoas que não sabem ler podem acessar o que guardam os livros, mas dependem de um terceiro que decifre e muitas vezes interprete o que diz o código da letra. Para a formação de um leitor, feita na maioria das vezes pela escola, é preciso mais que a aprendizagem do código, da decodificação e até mesmo da construção de sentido do texto. É necessária a compreensão do que se faz quando se lê e, ainda, do que significa não ler. 
É importante ressaltar que as pessoas podem, é claro, informar-se por outros meios que não dependam de leitura: conversando umas com as outras, ouvindo programas de rádio, assistindo à televisão etc. Assim, se estamos mesmo dispostos a pensar a biblioteca pública, eis as primeiras perguntas que temos que responder: por que ler é importante e em que a leitura difere de outras formas de acesso ao conhecimento? Dito de outra maneira: o que a leitura da letra nos oferece exclusivamente?

Antoine Compagnon, fazendo a defesa da literatura como forma privilegiada, mas não única, de falar sobre e de compreender a vida humana, contemporiza o discurso inflamado que se faz em torno da literatura, mas ressalta um aspecto exclusivo seu:

Certamente quem pode 0 mais pode 0 menos, mas as argumentações a favor de só a literatura, só a leitura, só o romance se fecham na defensiva, pois não é preciso reclamar tais privilégios. (...) Todas as formas de narração, que compreendem o filme e a história, falam-nos da vida humana. O romance o faz, entretanto, com mais atenção que a imagem móvel e mais eficácia que a anedota policial, pois seu instrumento penetrante é a língua, e ele deixa toda a sua liberdade para a experiência imaginária e para a deliberação moral, particularmente na solidão prolongada da leitura. Aí o tempo é meu. Sem dúvida posso suspender o desenrolar do filme, pará-lo em uma imagem, mas ele durará sempre uma hora e meia, ao passo que eu dito o ritmo de minha leitura e das aprovações e condenações que ela suscita em mim. (COMPAGNON, 2009, p. 54-55)

Se ampliamos para a leitura também de outros gêneros textuais a defesa que o autor faz da leitura de literatura, aproximação perfeita e coerentemente possível, compreendemos o que a leitura do texto escrito nos oferece exclusivamente: a produção de sentido, a percepção do mundo, o conhecimento, pelo que nos funda mais intimamente: a palavra. A palavra de um outro, escrita há uma hora ou há um milênio, na sala ao lado ou em outro canto do mundo.

Luiz Percival Leme Britto também atribui à leitura um caráter especial na construção do pensamento, para além do conteúdo contido no que se lê:

[Ler] é um instrumento intelectual importante, articulando o domínio de discursos e formas de pensar bastante específicas; é uma ação tipicamente metacognitiva, já que no momento em que lê, a pessoa não apenas explora um conteúdo como reflete sobre o texto que o apresenta de maneira muito mais intensa do que o que ocorre com outros meios; é uma situação que favorece o pensamento reflexivo e analítico, já que supõe monitoramento ativo e consciente da atividade intelectual; é uma possibilidade aguda de experiência estética sobre um objeto cultural intensamente elaborado e reelaborado. (BRITTO, 2003, p. 134) 
Destacada a especificidade da leitura, o próximo passo é compreender os discursos que a envolvem, desde sua polissemia até as crenças que sustentam sua divulgação e valorização.

A palavra leitura, como discute Luiz Percival Leme Britto (2012), vem sendo empregada em diferentes contextos: usa-se o termo em acepções e com objetivos distintos, muitas vezes sem qualquer vínculo com 0 ato de decodificar e atribuir sentido a um texto escrito. Da "leitura do mundo" freireana à leitura de imagens, passando pela leitura do jogo, do tempo, de filmes, dos lábios, das mãos etc., o termo assume muitos significados. Sem fazer juízo de valor quanto a um ou outro emprego da palavra, é importante que façamos as distinções necessárias quando lidamos com a pedagogia da leitura.

Da mesma forma que o uso do termo leitura, as campanhas publicitárias, governamentais e editoriais, para sua valorização como prática cultural e para a comercialização de livros e autores, assim como postagens individuais em perfis em redes sociais na internet, apóiam-se nos mais distintos entendimentos sobre a questão, mas, de maneira geral, apontando para uma compreensão restrita e ingênua do assunto.

A primeira e mais freqüente delas é a da leitura como algo bastante acessível e fácil, bastando o candidato a leitor se dispor a ler. Slogans como "ler é uma viagem", "ler é uma aventura", "embarque no maravilhoso mundo da leitura", "ler, é só começar" etc. demonstram a compreensão da leitura como algo fácil, isento de trabalho e à disposição de quem quiser, como um produto qualquer numa prateleira de supermercado.

Tão alardeado quanta a compreensão da leitura fácil, é o discurso do prazer. Com frases e propagandas bastante semelhantes, a leitura, especialmente a literária, é apresentada como fonte inesgotável de prazer e de lazer. Tanto o discurso da leitura fácil, da evasão aventureira por mundos maravilhosos, quanto o do prazer não contemplam no ato de ler o trabalho da leitura. Para ler, é preciso desenvolver habilidades lingüísticas, dedicar tempo à leitura, enfrentar as dificuldades apresentadas por um texto mais exigente e não desanimar com elas, muitas vezes estar sozinho, em silêncio.

Quando associados à leitura, termos como prazer e lazer precisam ser questionados. A promessa de prazer não é de todo equivocada, mas a trajetória a ser percorrida entre a letra e a experimentação prazerosa e até mesmo sua existência é, muitas vezes, desconhecida por professores, bibliotecários, editores e gestores públicos que nisso sustentam suas proposições e ações. Para um leitor, ler é prazeroso: há deleite nas imagens produzidas pelas palavras, nas associações de ideias deflagradas pelo texto, na beleza construída pela escrita, na liberdade conquistada pelo pensamento, no tangenciamento da fantasia e até mesmo no sofrimento partilhado por um personagem. Porém, alcançar a condição de leitor que se abre a esse tipo de prazer exige trabalho, pois esse prazer não se estabelece somente pelo conteúdo do que se lê, mas pela junção de forma e conteúdo e pela compreensão do que se faz quando se lê. Candido (2004, p. 178) aborda a importância da forma, das palavras 
escolhidas e ajuntadas de tal ou qual maneira em um texto, oral ou escrito:

Quando digo que um texto me impressiona, quero dizer que ele impressiona porque a sua possibilidade de impressionar foi determinada pela ordenação recebida de quem o produziu. Em palavras usuais: o conteúdo só atua por causa da forma, e a forma traz em si, virtualmente, uma capacidade de humanizar devido à coerência mental que pressupõe e que sugere.

Assim, a sensação agradável e divertida de conhecer uma história, seu enredo, como a oferecida por uma telenovela, por exemplo, é bastante distinta do prazer vislumbrado no pacto entre um leitor e o texto. Ler e encontrar prazer na leitura pressupõe disposição para o trabalho intelectual: em primeiro lugar, é preciso decidir ler e encontrar tempo e condições para isso. Depois, são necessárias as habilidades lingüísticas para decifrar o código e transformá-lo em conteúdo. Junto a tudo isso, o conhecimento e o desvendamento das formas, inferências e analogias, conscientes e inconscientes, com outros conhecimentos, tempo de contemplação e reflexão, dentre muitos outros fatores. Desse modo, a promessa de prazer feita pela leitura em nada se aproxima do lazer e do entretenimento, mas se traduz numa convocação ao exercício intelectual e num convite a questionamentos.

O terceiro ponto a ser considerado é a crença na leitura redentora, que vai contribuir para o progresso individual, para a consolidação da democracia e para conquistas sociais no país; para melhores empregos, melhores salários, uma sociedade mais justa etc. Num país de intensas desigualdades sociais como o Brasil, a educação se coloca como uma das poucas possibilidades de crescimento e melhoria de condições de vida para sua população, especialmente para as classes menos favorecidas economicamente. Essa é uma questão bastante delicada e exige cuidados em sua análise. Se apostamos e investimos na educação, na leitura e na escrita como forma de deslocamento, de promoção do ser humano, de rompimento com destinos previamente traçados por condições socioeconômicas historicamente determinadas, não podemos apagar a luz no fim do túnel. Sim, precisamos trabalhar para que a educação intelectual se sustente como uma esperança, como uma promessa de melhores condições de vida, não apenas do ponto de vista material, mas especialmente pela possibilidade de ampliação de liberdades, como Amartya Sen (2010), prêmio Nobel de Economia, define o desenvolvimento humano:

A despeito de aumentos sem precedentes na opulência global, o mundo atual nega liberdades elementares a um grande número de pessoas - talvez até mesmo à maioria. Às vezes a ausência de liberdades substantivas relaciona-se diretamente com a pobreza econômica, que rouba das pessoas a liberdade de saciar a fome, de 
obter uma nutrição satisfatória ou remédios para doenças tratáveis, a oportunidade de vestir-se ou morar de modo apropriado, de ter acesso a água tratada ou saneamento básico. Em outros casos, a privação de liberdade vincula-se estreitamente à carência de serviços públicos e assistência social, como por exemplo a ausência de programas, de um sistema bem planejado de assistência médica e educação ou de instituições eficazes para a manutenção da paz e da ordem locais. Em outros casos, a violação da liberdade resulta diretamente de uma negação de liberdades políticas e civis por regimes autoritários e de restrições impostas à liberdade de participar da vida social, política e econômica da comunidade. (SEN, 2010, p. 17)

Por outro lado, não podemos atribuir e esperar da leitura, e da educação, numa abordagem mais ampla, a solução de todos os problemas sociais do país. As políticas públicas para a formação de leitores, para a manutenção e o fortalecimento de bibliotecas precisam estar inseridas em programas mais abrangentes, que tenham em seu bojo a resolução de problemas históricos brasileiros, em consonância com outras políticas sociais. Não podemos desconsiderar que as condições para a apropriação da leitura estão ligadas às questões sociais, econômicas e culturais da população, num pensamento de que "é possível incluir toda a gente sem modificar o modelo excludente de sociedade" (BRITTO, 2003, p. 140); não podemos também desconsiderar a violência simbólica à qual as classes excluídas, não só do mundo da escrita, mas de inúmeros bens materiais e imateriais, são submetidas cotidianamente, seja na escola, no trabalho, na moradia, na saúde e na perspectiva de vida. Tomando como exemplo as bibliotecas públicas da Colômbia, que "são vistas como espaços de prevenção, de contenção, como uma possibilidade de ensaiar outros discursos" (REYES, 2012, p. 80), Yolanda Reyes alerta sobre a armadilha de se creditar à leitura e à biblioteca uma transformação que é complexa e dependente de muitas variáveis:

Uma armadilha porque não é suficiente corrigir os espaços simbólicos sem mudar a realidade, e por isso desconfio desses enfoques que conferem certo valor messiânico à promoção da leitura e que delegam às bibliotecas uma transformação de nossas condições de iniqüidade e de injustiça que são inadmissíveis e que competem ao Estado. (REYES, 2012, p. 80)

Ao que Britto (2003, p. 140) chama de "proselitismo da leitura", numa aproximação com os discursos e práticas religiosas que em busca de fiéis repetem exaustivamente uma fala pré-fabricada e dogmática, Castrillón (2011, p. 20) acrescenta, criticamente, suas considerações sobre o tema:

Tais campanhas, em geral, baseiam-se em palavras de ordem que pretendem nos convencer da necessidade dessa prática, 
sem levar em conta que nada se torna necessário - e muito menos a leitura, que é um exercício difícil, que exige um tempo cada vez mais escasso e um esforço que poucos estão dispostos a realizar - se não se tiver a íntima convicção de que ler pode ser um meio para melhorar as condições de vida e as possibilidades de ser, de estar e de atuar no mundo.

Assim, precisamos entender do que se fala quando se fala de leitura, pois é na compreensão dessa questão, ampla e complexa, ou na sua ausência, que se sustenta o entendimento do que é uma biblioteca pública, qual sua função social e, consequentemente, que apropriação a população fará dela.

A pesquisa Retratos da leitura no Brasil, idealizada e realizada por instituições ligadas ao mercado editorial desde 2000 e amplamente aceita pelo Ministério da Cultura como documento norteador das políticas públicas para a área, traz, em sua terceira edição, realizada em 2011 e publicada em 2012, as seguintes definições para leitor e não-leitor, respectivamente: "aquele que leu, inteiro ou em partes, pelo menos 1 livro nos últimos 3 meses" e "aquele que não leu, nenhum livro nos últimos 3 meses, mesmo que tenha lido nos últimos 12 meses" (FAILLA, 2012, p. 254).

Este "modelo" de leitor pressupõe um modelo de biblioteca pública que o abrigará: seu acervo, seus serviços, suas atividades, seu horário de funcionamento serão direcionados para o atendimento e o alcance de um leitor que se define por um critério quantitativo.

Em contraponto ao entendimento de leitor apresentado pela terceira edição da Retratos da leitura no Brasil, tomamos a compreensão professada por Nilma Lacerda ([200-], p. 16), que aponta em outra direção:

o livre-arbítrio - que torna os seres humanos responsáveis por seus atos - encontra sustento devido na informação e no arcabouço reflexivo que caracterizam a condição de leitor. Ler não é tão-somente uma ação pragmática, porém um exercício da razão e do devaneio - duas faces que compõem a mente humana, como cara e coroa fazem o todo de uma moeda. (...) leitores costumam ser formuladores de perguntas e capazes, como tal, de escrever sentenças diversas das que lhes foram ensinadas como as únicas possíveis, verdadeiras ou legítimas. O fato de ser leitor traz como única garantia a perspectiva da escrita como tarefa aberta, inacabada, que a humanidade confia a si própria, na possibilidade de exercer o melhor de sua condição.

Da mesma maneira, essa compreensão da leitura e do leitor exige um desenho de biblioteca que a concretize. Assim, será outro o acervo, 
serão outras as atividades e os serviços oferecidos, o horário de funcionamento atenderá a outra lógica.

A biblioteca que adota como definição de leitor o entendimento da Retratos da leitura no Brasil tem uma tarefa relativamente fácil: fazer com que as pessoas leiam, pelo menos, um livro ou partes dele a cada três meses. Não importa de que natureza seja esse livro ou o que se considera uma parte dele; não é relevante o que essa leitura provocou ou pode provocar na vida de cada um dos considerados leitores. O que é válido e importante neste modelo é o número que alimenta as estatísticas, a meta a ser alcançada. O compromisso da biblioteca passa a ser com planilhas, com dados que dizem nada ou muito pouco sobre sua atuação.

Já o trabalho por leitores "formuladores de perguntas e capazes, como tal, de escrever sentenças diversas das que Ihes foram ensinadas como as únicas possíveis, verdadeiras ou legítimas" exige muito mais da biblioteca pública. Em primeiro lugar, são necessários profissionais que entendam a participação no mundo da escrita, para além das competências de ler e escrever, que tenham a compreensão desse universo e o que sua participação ou ausência implicam na vida do sujeito, mesmo que em algumas etapas da vida, como na primeira infância, por exemplo, isso nem sempre esteja sistematizado para o próprio sujeito. Outro ponto que não se pode perder de vista é que a escrita e as formas com que é ofertada e permitida representam, sempre, um lugar de poder, uma vez que o mundo formal é organizado e regido pela letra. A participação no mundo da escrita é condição para a educação intelectual dos sujeitos e deve ultrapassar as questões cotidianas e imediatas, não restringindo seu horizonte ao alfabetismo funcional, isto é, a exclusiva instrumentalização da população, mediante o desenvolvimento de habilidades de leitura e escrita, para as práticas sociais, para a realização de tarefas da vida urbano-industrial.

Entre Procrusto e Crispino, com todas as possibilidades, conflitos, contradições e dificuldades que possam existir no que se coloca neste intervalo, estão os profissionais e, consequentemente, as proposições que se constroem para as bibliotecas públicas brasileiras. Cabe a nós, profissionais da área e às escolas de Biblioteconomia, que nos formam, compreender do que falamos e o que buscamos quando tratamos de bibliotecas públicas. Radicalmente, são duas as opções: a biblioteca pública como espaço de conformação, de resposta ao sistema produtivo e a serviço do utilitarismo, traduzida em acervos bibliográficos que apenas atendem às demandas dos usuários, em atividades de entretenimento que dispensam os participantes do trabalho intelectual, em respostas a perguntas prontas elaboradas por terceiros, que oferecem aos sujeitos mais do mesmo que eles já têm e os mantêm, satisfeitos, em seus lugares; ou a biblioteca que se abre para o mediato, para o tempo livre do capital, para a extrapolação do cotidiano por meio da história, das narrativas e do conhecimento registrados, ao longo do tempo e do espaço, pela escrita.

\section{Referências}


ADORNO, Theodor W. Educação e emancipação. Rio de Janeiro: Paz e Terra, 1995.

BARTHES, Roland. Aula. São Paulo: Cultrix, [19--].

BRANDÃO, Junito de Souza. Mitologia grega. Petrópolis: Vozes, 2000. v. 3.

BRITTO, Luiz Percival Leme. Contra o consenso: cultura escrita, educação e participação. Campinas, SP: Mercado de Letras, 2003.

BRITTO, Luiz Percival Leme. Inquietudes e desacordos: a leitura além do óbvio. Campinas, SP: Mercado de Letras, 2012.

CALVINO, Ítalo. Um general na biblioteca. São Paulo: Companhia das Letras, 2001.

CANDIDO, Antonio. Vários escritos. Rio de Janeiro: Ouro sobre Azul; São Paulo: Duas Cidades, 2004.

CASTRILLÓN, Silvia. O direito de ler e de escrever. São Paulo: Pulo do Gato, 2011.

CLARK, T. J. Por uma esquerda sem futuro. São Paulo: Ed. 34, 2013.

COMPAGNON, Antoine. Literatura para quê?. Belo Horizonte: Ed., UFMG, 2009.

FAILLA, Zoara (Org.). Retratos da leitura no Brasil 3. São Paulo: Imprensa Oficial do Estado de São Paulo: Instituto Pró-Livro, 2012.

MUELLER, Suzana P. M. Bibliotecas e sociedade: evolução da interpretação de função e papéis da biblioteca. Revista da Escola de Biblioteconomia da UFMG, Belo Horizonte, v. 13, n. 1, p. 7-54, mar. 1984.

REYES, Yolanda. Ler e brincar, tecer e cantar: literatura, escrita e educação. São Paulo: Pulo do Gato, 2012.

SEN, Amartya. Desenvolvimento como liberdade. São Paulo: Companhia das Letras, 2010. 